\title{
Papers
}

\section{Use of clinical syndromes to target antibiotic prescribing in seriously ill children in malaria endemic area: observational study}

James A Berkley, Kathryn Maitland, Isaiah Mwangi, Caroline Ngetsa, Saleem Mwarumba, Brett S Lowe, Charles R J C Newton, Kevin Marsh, J Anthony G Scott, Mike English

\begin{abstract}
Objectives To determine how well antibiotic treatment is targeted by simple clinical syndromes and to what extent drug resistance threatens affordable antibiotics.

Design Observational study involving a priori definition of a hierarchy of syndromic indications for antibiotic therapy derived from World Health Organization integrated management of childhood illness and inpatient guidelines and application of these rules to a prospectively collected dataset. Setting Kilifi District Hospital, Kenya.

Participants 11847 acute paediatric admissions.

Main outcome measures Presence of invasive bacterial infection (bacteraemia or meningitis) or Plasmodium falciparum parasitaemia; antimicrobial sensitivities of isolated bacteria. Results 6254 (53\%) admissions met criteria for syndromes requiring antibiotics (sick young infants; meningitis/ encephalopathy; severe malnutrition; very severe, severe, or mild pneumonia; skin or soft tissue infection): 672 (11\%) had an invasive bacterial infection ( $80 \%$ of all invasive bacterial infections identified), and 753 (12\%) died (93\% of all inpatient deaths). Among $P$ falciparum infected children with a syndromic indication for parenteral antibiotics, an invasive bacterial infection was detected in 4.0-8.8\%. For the syndrome of meningitis/encephalopathy, 96/123 (76\%) isolates were fully sensitive in vitro to penicillin or chloramphenicol.

Conclusions Simple clinical syndromes effectively target children admitted with invasive bacterial infection and those at risk of death. Malaria parasitaemia does not justify withholding empirical parenteral antibiotics. Lumbar puncture is critical to the rational use of antibiotics.
\end{abstract}

\section{Introduction}

Invasive bacterial infections are an important cause of childhood illness and death worldwide. To develop effective guidelines for initial antimicrobial treatment, knowledge of the likely cause of illness and the pattern of antibiotic resistance are fundamental. However, many resource poor countries lack local data and look to the World Health Organization for guidance. Advice on the management of common conditions has recently been summarised in the context of the integrated management of childhood illness approach. ${ }^{1}$ Diagnosis in such settings usually depends on the identification of a small number of clinical syndromes. Seriously ill children often meet criteria for several clinical syndromes, however, and different diseases may cause the same clinical syndrome. ${ }^{2}$ In malaria endemic areas uncertainty may exist because the clinical manifestations of malaria overlap with those of pneumonia, bacteraemia, and meningitis. ${ }^{3-12}$

We aimed to determine how well antibiotic treatment is targeted by simple rules based on current WHO guidelines, how application of such rules is affected by malaria parasitaemia in an endemic area, and to what extent antibiotic resistance threatens the use of cheap antibiotics. These analyses aim to reflect the practical decisions faced by clinicians, rather than simply describing the antimicrobial sensitivities of individual bacterial species or the bacterial aetiology of diseases defined at discharge.

\section{Methods}

\section{Location and clinical methods}

Kilifi District Hospital is located in a rural area on the Kenyan coast; a Kenya Medical Research Institute centre is based at the hospital. Children receive up to 50 mosquito bites infective for Plasmodium falciparum annually, with two transmission seasons. ${ }^{13}$ Ten per cent of women attending the hospital antenatal clinic in 2000 were infected with HIV. ${ }^{14}$ Haemophilus influenzae type b conjugate vaccination had not begun at the time of the study. Government employed clinical officers, without training in the integrated management of childhood illness, referred children to the paediatric wards.

We recruited all children admitted from February 1999 to December 2001, unless a clinically obvious disorder was present that was unlikely to cause diagnostic uncertainty, such as elective surgery, trauma, sickle cell crisis, congenital anomalies, tetanus, or nephrotic syndrome. ${ }^{2}$ We collected clinical data, a malaria slide, full blood count, and blood culture on admission. ${ }^{15}{ }^{16}$ Table 1 gives clinical definitions. Our lumbar puncture policy included any of the following at any time during admission: meningism; impaired consciousness (delayed until neurologically stable); prostration in children aged under 3 years; and seizures, other than simple febrile seizures or as a septic screen in young infants. ${ }^{17}$ Inpatient treatment followed WHO and local guidelines, including recommended protocols for severe malnutrition. ${ }^{1}$

\section{Laboratory methods}

We used a BACTEC 9050 instrument (Becton Dickinson, USA) to process blood cultures, and further processed them by standard methods. We regarded Staphylococcus epidermidis, Streptococcus viridans, Bacillus, or Micrococcus species as contaminants. We counted the leucocytes in cerebrospinal fluid (CSF) in a modified Neubauer chamber and did Gram stain and latex agglutination for Haemophilus influenzae type b and Streptococcus pmeumoniae (Murex Diagnostics, UK) if $>10$ leucocytes/ $\mu$ l were present. We 
Table 1 Definition of clinical syndromes and currently recommended antibiotic treatment

\begin{tabular}{|c|c|c|}
\hline Syndrome & Definition & $\begin{array}{l}\text { Recommended antibioti } \\
\text { treatment* }\end{array}$ \\
\hline Sick young infants & $\begin{array}{l}\text { Any child }<60 \text { days old sick } \\
\text { enough to warrant admission } \\
\text { to hospital }\end{array}$ & $\begin{array}{l}\text { Gentamicin with either } \\
\text { penicillin or ampicillin }\end{array}$ \\
\hline Meningitis/encephalopathy & $\begin{array}{l}\text { Neck stiffness, bulging } \\
\text { fontanel, or impaired } \\
\text { consciousness } \dagger\end{array}$ & $\begin{array}{l}\text { Penicillin with } \\
\text { chloramphenicol }\end{array}$ \\
\hline Severe malnutrition & $\begin{array}{l}\text { Severe wasting } \neq \text { or } \\
\text { kwashiorkor }\end{array}$ & $\begin{array}{l}\text { Gentamicin with either } \\
\text { penicillin or ampicillin }\end{array}$ \\
\hline Very severe pneumonia & $\begin{array}{l}\text { Respiratory distress§ plus } \\
\text { one or more of prostrationfl, } \\
\text { cyanosis, or hypoxia** }\end{array}$ & Chloramphenicol \\
\hline Severe pneumonia & Respiratory distress§ & Penicillin \\
\hline Mild pneumonia & $\begin{array}{l}\text { Tachypnoeat† plus a history } \\
\text { of either cough or difficulty } \\
\text { breathing }\end{array}$ & Oral amoxicillin \\
\hline Skin or soft tissue infection & $\begin{array}{l}\text { Cellulitis, abscess, } \\
\text { pyomyositis }\end{array}$ & Cloxacillin \\
\hline
\end{tabular}

*Parenteral unless otherwise indicated.

†Blantyre coma score $\leq 2 .^{5}$

fWeight for age $z$ score $<-4$ by NCHS standards (Epi Info 2000, CDC, Atlanta, USA).

$\S$ Lower chest wall indrawing or abnormally deep breathing.

IInability to sit unassisted if aged $\geq 1$ year or inability to drink or breastfeed if aged $<1$ year.

${ }^{*} \mathrm{SaO}_{2}<90 \%$ in air by pulse oximetry (Nellcor, USA).

$\dagger \dagger \geq 50$ breaths per minute if aged 60 days to 1 year; $\geq 40$ breaths per minute if $\geq 1$ year old. ${ }^{1}$

assayed glucose in CSF and a concurrent blood sample (Analox Ltd, UK). We defined bacterial meningitis as positive CSF culture, positive CSF latex agglutination test, organisms on Gram stain, CSF leucocytes $\geq 50 / \mu \mathrm{l}$, or CSF:blood glucose ratio $<0.1$. $^{17}$ Antibiotic susceptibilities were determined at the end of the study (E-test, AB Biodisk, Sweden) at the manufacturer's laboratory and interpreted using National Committee for Clinical Laboratory Standards guidelines. ${ }^{18}$ We defined in vitro sensitivity as "fully sensitive" for children with meningitis and "fully sensitive" or "intermediately sensitive" for children without meningitis. Isolates from children aged 60 days or older with confirmed meningitis were classified as resistant to gentamicin because of poor CSF penetration. Isolates were tested against individual antibiotics, and sensitivity to an antibiotic combination was defined as sensitivity to either of the antibiotics alone. Blood counts were automated (Beckman/Coulter Inc, USA). For malaria diagnosis, we stained a thick and thin blood slide with Giemsa and examined it at x1000. Laboratory procedures were internally and externally quality controlled (www.neqas.com).

\section{Analysis}

For the purposes of this analysis only, we classified children as meeting the definition of a syndrome warranting antibiotic treatment (table 1) or not by using data collected on admission. We constructed an a priori hierarchy of the syndromes, reflecting prioritisation in clinical practice (figure). We did not use the outpatient integrated management of childhood illness syndrome of "very severe febrile disease," ${ }^{19}$ as we would expect referral care to be further rationalised. We assigned individual children to their highest priority syndrome. We compared proportions by using Fisher's exact test and explored the possibility that antibiotic resistance increased the risk of inpatient death by using multiple logistic regression. We labelled individuals as "resistant to treatment" if the organism isolated was resistant in vitro to the antibiotics defined by their syndrome. Terms included in the multiple regression model included age ( $<7$ or $\geq 7$ days), sex, meningitis, malnutrition, and malaria. We used Stata version 8.0 for statistical analysis.

\section{Results}

Among 14987 admissions, we excluded 1254 (8.4\%) with an obvious diagnosis, $134(<1 \%)$ with missing data or refusal to consent, and $1752(12 \%)$ with contaminated blood cultures, leaving 11847 admissions (table 2). We detected an invasive bacterial infection in $843(7.1 \%)$ admissions (table 3$)$ : $633(5.3 \%)$ positive blood culture only, $9(<0.1 \%)$ positive CSF culture only, 111 $(0.9 \%)$ positive blood and CSF cultures, $21(0.2 \%)$ positive blood culture with CSF evidence of meningitis, and $69(0.6 \%)$ CSF evidence of meningitis but negative cultures. We detected $P$ falciparum parasitaemia in $5270(45 \%)$ admissions. A defined syndrome requiring antibiotics was present in 6254 (53\%) admissions; of these, $672(11 \%)$ had an invasive bacterial infection, representing $80 \%$ of all invasive bacterial infections, and $753(12 \%)$ died in hospital, representing 93\% of 813 inpatient deaths.

\section{Sick young infants}

Of 1267 young infants, $184(15 \%)$ had an invasive bacterial infection (table 3), principally group B streptococci, E coli, Acinetobacter, and Klebsiella spp (table 4). The proportion of isolates susceptible in vitro to ampicillin-gentamicin was greater than that resistant to either penicillin-gentamicin or cefotaxime (both $\mathrm{P}=0.001)($ table 5).

\section{Meningitis/encephalopathy syndrome}

This clinical syndrome captured 101/160 (63\%) cases of laboratory defined meningitis in children at least 60 days old; 21 (13\%) other cases of meningitis outside this syndrome definition met another syndrome definition indicating parenteral antibiotics. The remaining 38 (24\%) cases of meningitis would not have initially received parenteral antibiotics if syndromic treatment rules (that do not rely on lumbar puncture) had been followed

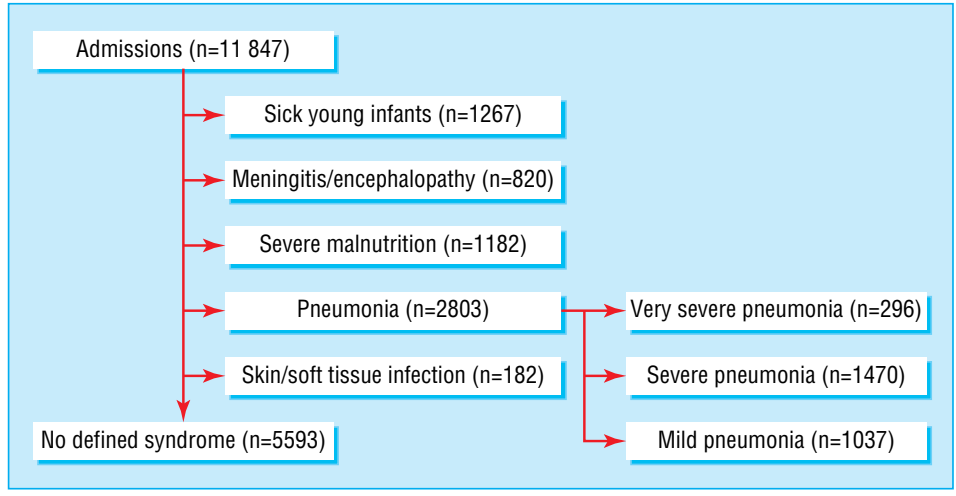

Hierarchical classification of defined syndromes requiring antibiotic treatment 
Table 2 Clinical characteristics of study participants. Values are numbers (percentages) unless stated otherwise

\begin{tabular}{lc} 
Characteristic & Participants* (n=11 847) \\
\hline Median (interquartile range) age (months) & $17(7$ to 35) \\
\hline Girls & $5494(46)$ \\
\hline History of fever & $9822 / 11838(83)$ \\
\hline History of cough & $5275 / 11838(45)$ \\
\hline History of difficulty breathing & $4065 / 11838(34)$ \\
\hline History of diarrhoea & $2545 / 11838(22)$ \\
\hline History of convulsions & $2719 / 11837(23)$ \\
\hline Mean (SD) weight for age $\mathrm{z}$ score & $-1.84(1.50)$ \\
\hline Kwashiorkor & $766 / 11833(6.5)$ \\
\hline Axillary temperature $\geq 37.5^{\circ} \mathrm{C}$ & $7273 / 11813(62)$ \\
\hline Impaired consciousness & $734 / 11835(6.2)$ \\
\hline Tachypnoea & $4064 / 11741(35)$ \\
\hline Subcostal indrawing & $2317 / 11834(20)$ \\
\hline Deep breathing & $737 / 11836(6.2)$ \\
\hline Anaemia (Hb<8 $\mathrm{g} / \mathrm{dl})$ & $4584 / 11813(39)$ \\
\hline Severe anaemia $(\mathrm{Hb}<5 \mathrm{~g} / \mathrm{dl})$ & $1173 / 11813(9.9)$ \\
\hline Malaria parasitaemia & $5270 / 11786(45)$ \\
\hline${ }^{*}$ Denominators less than 11847 indicate missing data. &
\end{tabular}

absolutely. The most common isolates were $S$ pneumoniae and $H$ influenzae (table 4). Four hundred and twenty two (52\%) children with this syndrome had a positive malaria slide; $29(6.9 \%)$ of these had an invasive bacterial infection compared with 117/397 $(30 \%)$ children with negative slides $(\mathrm{P}<0.001$, table 3). Case fatality did not vary significantly with malaria parasitaemia. Only $76 \%$ of isolates were fully sensitive in vitro to penicillinchloramphenicol compared with $93 \%$ for cefotaxime $(\mathrm{P}<0.001$, table 5). When we excluded $H$ influenzae, $86 \%$ of isolates were sensitive to penicillin-chloramphenicol. Susceptibility results were similar when all meningitis cases missed by this syndrome definition were included.

\section{Severe malnutrition syndrome}

Severe malnutrition syndrome accounted for 141/659 (21\%) of invasive bacterial infections and 200/533 (38\%) of deaths in children aged at least 60 days (table 3). S pneumoniae, E coli, and nontyphoidal salmonellae were the most common isolates (table 4). Most $(959,81 \%)$ of these admissions did not meet criteria for another syndrome requiring antibiotics, making anthropometry or kwashiorkor the sole basis for antibiotic treatment. Of these,

Table 3 Number of admissions with defined syndromes, prevalence of invasive bacterial infections, malaria parasitaemia, and outcome. Values are numbers (percentages) unless stated otherwise

\begin{tabular}{|c|c|c|c|c|c|c|c|}
\hline \multirow[b]{2}{*}{ Syndrome } & \multirow{2}{*}{$\begin{array}{l}\text { Median (IQR) age } \\
\text { (months) }\end{array}$} & \multirow{2}{*}{$\begin{array}{c}\text { Invasive } \\
\text { bacterial } \\
\text { infection* }\end{array}$} & \multirow[b]{2}{*}{ Meningitis } & \multirow[b]{2}{*}{ Deaths } & \multirow{2}{*}{$\begin{array}{l}\text { Malaria slide } \\
\text { positive }\end{array}$} & \multicolumn{2}{|c|}{ Invasive bacterial infection* } \\
\hline & & & & & & Malaria positive & Malaria negative \\
\hline Sick young infants $(n=1267)$ & 7 (2-22) days & $184(15)$ & $50(4.0)$ & $280(22)$ & $34(2.7)$ & $2 / 34 \quad(5.9)$ & $176 / 1213(15)$ \\
\hline $\begin{array}{l}\text { Meningitis/encephalopathy } \\
(\mathrm{n}=820)\end{array}$ & $27(13-46)$ & $147(18)$ & $101(12)$ & $150(18)$ & $422(52)$ & $29 / 422(6.9)$ & $117 / 397 \quad(30)$ \\
\hline Severe malnutrition $(\mathrm{n}=1182)$ & $24(15-39)$ & $141(12)$ & $3(0.3)$ & $200(17)$ & $376(32)$ & $33 / 376(8.8)$ & 108/802 (13) \\
\hline $\begin{array}{l}\text { Very severe pneumonia } \\
(\mathrm{n}=296)\end{array}$ & $13(5-29)$ & $33(11)$ & $8(2.7)$ & $56(19)$ & $124(42)$ & $5 / 124(4.0)$ & $28 / 172(16)$ \\
\hline Severe pneumonia $(n=1470)$ & $10(5-20)$ & $88(6.0)$ & $5(0.3)$ & $52(3.5)$ & $455(31)$ & $18 / 455(4.0)$ & $69 / 1004(6.9)$ \\
\hline Mild pneumonia $(n=1037)$ & $17(10-29)$ & $69(6.7)$ & $8(0.8)$ & $15(1.5)$ & $526(51)$ & $16 / 526(3.0)$ & $52 / 509(10)$ \\
\hline $\begin{array}{l}\text { Skin/soft tissue infection } \\
(n=182)\end{array}$ & $19(10-36)$ & $10(5.5)$ & 0 & 0 & $86(47)$ & $1 / 86(1.2)$ & 9/95 (9.5) \\
\hline $\begin{array}{l}\text { No defined syndrome } \\
(\mathrm{n}=5593)\end{array}$ & $23(11-44)$ & $171(3.1)$ & $35(0.6)$ & $60(1.1)$ & $3247(58)$ & $53 / 3247(1.6)$ & $118 / 2324(5.1)$ \\
\hline All admissions $(n=11$ 847) & $17(7-35)$ & $843(7.1)$ & $210(1.8)$ & $813(6.9)$ & $5270(45)$ & $157 / 5270(3.0)$ & $677 / 6516(10)$ \\
\hline
\end{tabular}

IQR=interquartile range.

*Includes meningitis and bacteraemia.

Table 4 Bacterial isolates cultured. Values are numbers (percentages ${ }^{\star}$ )

\begin{tabular}{|c|c|c|c|c|c|c|c|c|c|}
\hline Bacterial isolates & $\begin{array}{l}\text { Sick young } \\
\text { infants }\end{array}$ & $\begin{array}{l}\text { Meningitis/ } \\
\text { encephalitis }\end{array}$ & $\begin{array}{c}\text { Severe } \\
\text { malnutrition }\end{array}$ & $\begin{array}{l}\text { Very severe } \\
\text { pneumonia }\end{array}$ & $\begin{array}{c}\text { Severe } \\
\text { pneumonia }\end{array}$ & Mild pneumonia & $\begin{array}{l}\text { Skin/soft tissue } \\
\text { infection }\end{array}$ & $\begin{array}{l}\text { No defined } \\
\text { syndrome }\end{array}$ & Total \\
\hline \multicolumn{10}{|l|}{ Gram positive } \\
\hline $\begin{array}{c}\text { Streptococcus } \\
\text { pneumoniae }\end{array}$ & $13(8)$ & $47(37)$ & $40(27)$ & $14(44)$ & $28(31)$ & $29(43)$ & $1(10)$ & $30(19)$ & 202 \\
\hline $\begin{array}{l}\text { Staphylococcus } \\
\text { aureus }\end{array}$ & $16(9)$ & $5(4)$ & $5(3)$ & 1 (3) & $2(2)$ & $3(4)$ & $4(40)$ & $18(12)$ & 54 \\
\hline Group A streptococci & $13(8)$ & $5(4)$ & $3(2)$ & $2(6)$ & 0 & 1 (1) & $1(10)$ & $5(3)$ & 30 \\
\hline Group B streptococci & $20(12)$ & 0 & 0 & 0 & 0 & 0 & 0 & 0 & 20 \\
\hline Other Gram positives† & $8(5)$ & 1 (1) & $4(3)$ & $1(3)$ & 0 & $4(6)$ & 0 & $4(3)$ & 22 \\
\hline \multicolumn{10}{|l|}{ Gram negative } \\
\hline $\begin{array}{r}\text { Non-typhoidal } \\
\text { salmonellae }\end{array}$ & $3(2)$ & $9(7)$ & $25(17)$ & $2(6)$ & $18(20)$ & $16(24)$ & 0 & $44(28)$ & 117 \\
\hline $\begin{array}{c}\text { Haemophilus } \\
\text { influenzae }\end{array}$ & $8(5)$ & $36(29)$ & $12(8)$ & $5(16)$ & $18(20)$ & $6(9)$ & 0 & $16(10)$ & 101 \\
\hline Escherichia coli & 19 (11) & $3(2)$ & $31(21)$ & $2(6)$ & $11(12)$ & $3(4)$ & 0 & $7(5)$ & 76 \\
\hline Acinetobacter sp & $17(10)$ & $6(5)$ & $9(6)$ & $2(6)$ & $6(7)$ & 1 (1) & $1(10)$ & $11(7)$ & 53 \\
\hline Klebsiella sp & $17(10)$ & 1 (1) & $4(3)$ & $0(0)$ & $2(2)$ & 0 & $1(10)$ & $2(1)$ & 27 \\
\hline Pseudomonas sp & $9(5)$ & $6(5)$ & $2(1)$ & $1(3)$ & $2(2)$ & 1 (1) & $1(10)$ & $4(3)$ & 26 \\
\hline $\begin{array}{r}\text { Other Gram } \\
\text { negatives† }\end{array}$ & $30(17)$ & $7(6)$ & $13(9)$ & $2(6)$ & $2(2)$ & $4(6)$ & $1(10)$ & $14(9)$ & 73 \\
\hline$\overline{\text { Total }}$ & 173 & 126 & 148 & 32 & 89 & 68 & 10 & 155 & 801 \\
\hline
\end{tabular}

*Percentages refer to columns.

tOther common isolates in admissions $\geq 60$ days included group D streptococci (10), Campylobacter sp (4), Enterobacter sp (3), and Shigella sp (3). Other common isolates in young infants included Aeromonas sp (7), Enterobacter sp (7), and group D streptococci (6). 


\begin{tabular}{|c|c|c|c|c|c|c|c|c|}
\hline Antibiotics & $\begin{array}{l}\text { Young infants } \\
(\mathrm{n}=167)\end{array}$ & $\begin{array}{c}\text { Meningitis/ } \\
\text { encephalitis } \\
(n=123)\end{array}$ & $\begin{array}{c}\text { Severe } \\
\text { malnutrition } \\
(n=141)\end{array}$ & $\begin{array}{l}\text { Very severe } \\
\text { pneumonia } \\
\quad(\mathrm{n}=30)\end{array}$ & $\begin{array}{c}\text { Severe } \\
\text { pneumonia } \\
(\mathrm{n}=84)\end{array}$ & $\begin{array}{l}\text { Mild pneumonia } \\
\qquad(\mathrm{n}=64)\end{array}$ & $\begin{array}{l}\text { Skin/soft tissue } \\
\text { infection }(n=8)\end{array}$ & $\begin{array}{c}\text { No defined } \\
\text { syndrome } \\
\text { ( } n=141)\end{array}$ \\
\hline Amoxicillin/ampicillin & 55 & 70 & 57 & 73 & 56 & 72 & 50 & 59 \\
\hline Co-trimoxazole & 73 & 34 & 42 & 43 & 36 & 56 & 88 & 54 \\
\hline Benzyl penicillin & 31 & 33 & 32 & 50 & 34 & 47 & 38 & 28 \\
\hline Chloramphenicol & 76 & 76 & 77 & 83 & 74 & 83 & 100 & 81 \\
\hline Penicillin and gentamicin & 88 & 51 & 81 & 68 & 73 & 83 & 88 & 77 \\
\hline Ampicillin and gentamicin & 97 & 81 & 87 & 84 & 85 & 91 & 88 & 88 \\
\hline $\begin{array}{l}\text { Penicillin and } \\
\text { chloramphenicol }\end{array}$ & 82 & 76 & 77 & 83 & 74 & 83 & 100 & 82 \\
\hline Cefotaxime & 86 & 93 & 94 & 93 & 92 & 98 & 88 & 93 \\
\hline
\end{tabular}

${ }^{\star}$ E-test was done on $758(95 \%)$ isolates. Percentages refer to the proportion of isolates sensitive to the antibiotic or combination. For admissions with confirmed meningitis, sensitivity is taken as the NCCLS "sensitive" breakpoint. For children aged $\geq 60$ days with confirmed meningitis, isolates were classified as not susceptible to gentamicin because of poor penetration in cerebrospinal fluid. In admissions without meningitis, sensitivity is taken as NCCLS "intermediate" or "sensitive."

$88(9.2 \%)$ had an invasive bacterial infection and $153(16 \%)$ died, compared with $53(24 \%)$ and $47(21 \%)$ of the 223 who met other syndrome definitions (both $\mathrm{P}<0.001$ ). The prevalence of invasive bacterial infection was higher in children with negative malaria slides than in those with positive slides $(\mathrm{P}=0.02$, table 3$)$. Case fatality was lower in admissions with negative malaria slides $(166 / 802,21 \%)$ than in those with positive slides $(34 / 376,9.0 \%)$ $(\mathrm{P}<0.001)$. In vitro susceptibility to amoxicillin-gentamicin was greater than that to penicillin-gentamicin $(\mathrm{P}<0.05$, table 5$)$.

\section{Pneumonia syndromes}

Of 2803 (24\%) children admitted with a pneumonia syndrome, $1470(52 \%)$ had severe disease and $296(11 \%)$ had very severe disease. The prevalence of invasive bacterial infection with severe pneumonia syndrome was similar to that with mild pneumonia syndrome, but case fatality was greater $(\mathrm{P}=0.001$, table 3$)$. $S$ pneumoniae (38\%), Enterobacteriaceae (30\%), and $H$ influenzae $(15 \%)$ were the most common isolates (table 4). Three to four per cent of children with a positive malaria slide had an invasive bacterial infection compared with $6.9-16 \%$ in those with a negative slide (all $\mathrm{P}<0.001$, table 3 ). Case fatality did not vary significantly with malaria parasitaemia. Isolates from children with severe or very severe pneumonia were more commonly susceptible to chloramphenicol alone than to penicillin alone $(\mathrm{P}=0.05)$ and to ampicillin-gentamicin than to penicillin-gentamicin $(\mathrm{P}=0.04$, table 5).

\section{Skin or soft tissue infection syndrome}

Ten $(5.5 \%)$ of 182 children with skin or soft tissue infections had an invasive bacterial infection. Staphylococcus aureus accounted for four (40\%) invasive infections, and all these were sensitive to cloxacillin.

\section{No defined syndrome requiring antibiotics}

Of 5593 children without a syndrome requiring antibiotics, 171 $(3.1 \%)$ had an invasive bacterial infection and $60(1.1 \%)$ died. Non-typhoidal salmonellae, $S$ pneumoniae, and $S$ aureus were the most common isolates (table 4). Of 2324 malaria slide negative admissions, $118(5.1 \%)$ had an invasive bacterial infection compared with 53/3247 (1.6\%) slide positive admissions $(\mathrm{P}<0.001)$. Among children with an axillary temperature $\geq 39^{\circ} \mathrm{C}$, invasive bacterial infection was present in $47 / 488(9.6 \%)$ with a negative malaria slide compared with $22 / 1422(1.6 \%)$ with a positive slide $(\mathrm{P}<0.001)$. We found no significant association between invasive bacterial infection and prostration, seizures, diarrhoea, vomiting, jaundice, or severe anaemia. Among children with an invasive bacterial infection, $0 / 53$ children with a positive malaria slide died compared with 11/118 (9.3\%) of those with a negative slide $(\mathrm{P}=0.02)$. In those without an invasive bacterial infection, 20/3194 $(0.6 \%)$ children with a positive malaria slide died compared with 29/2216 (1.3\%) with a negative slide $(\mathrm{P}=0.009)$.

\section{Antimicrobial resistance and outcome}

Antibiotic resistance to recommended treatment was associated with an odds ratio of 1.22 (95\% confidence interval 0.78 to 1.92 ) for fatal outcome. If only deaths after 24 hours of admission were examined, the association with a fatal outcome strengthened (odds ratio $=1.90,0.95$ to 3.80 ), but the possibility of no association could not be absolutely excluded.

\section{Discussion}

Clinical officers and doctors at hospitals in sub-Saharan Africa face considerable challenges in managing seriously ill children, having few resources for diagnosis or treatment. Good early management is important because most deaths occur within 48 hours of admission. Initially, the management of seriously ill children is largely independent of the underlying cause. It includes resuscitation and correction of life threatening complications such as hypoxaemia, hypovolaemia, hypoglycaemia, convulsions, and severe anaemia. Antibiotics and antimalarials can be effective only if such complications are recognised and adequately treated.

\section{Syndromic rules effectively target children with invasive bacterial infections}

We have found that among acute paediatric admissions to a Kenyan district hospital, simple clinical syndromes based on WHO guidelines identified at admission $80 \%$ of children with an invasive bacterial infection and 93\% of subsequent inpatient deaths. For every nine children with a defined syndrome indicating antibiotic treatment, one child had an identified invasive bacterial infection. Given the likely insensitivity of blood culture, we think this justifies empirical antibiotic treatment.

Does a positive malaria slide justify withholding antibiotics? Overall, the presence of $P$ falciparum parasitaemia was associated with a lower risk of invasive bacterial infection. However, where a syndrome requiring parenteral antibiotics (meningitis/ encephalopathy, malnutrition, very severe or severe pneumonia) was present, children with a positive malaria slide (by quality controlled microscopy in a research setting) still had a risk of detectable invasive bacterial infection between 1 in 25 and 1 in 11 and a risk of dying between 1 in 28 and 1 in 6 (table 3 and results section). We believe that these risks are too high to justify withholding parenteral antibiotics because a malaria slide is positive. 
For children with the syndrome of mild pneumonia and a positive malaria slide, the case for withholding antibiotics strengthens: within this group, 1 in 33 had an identified invasive bacterial infection and 1 in 66 died. Given that blood cultures are less sensitive than other tests such as lung aspiration, ${ }^{20}{ }^{21}$ that treatment with oral amoxicillin is relatively inexpensive, and that the overall potential antibiotic pressure on resistance exerted by this group would be small, dual treatment of children in hospital, as is common in outpatient populations, ${ }^{8}$ seems justified.

The accuracy of reading malaria slides in the region is an important concern. Recent reports suggest that this investigation is commonly unreliable, with frequent false positives. ${ }^{22}{ }^{23}$ Among children with a clinical syndrome compatible with cerebral malaria, such false positives would have a 1 in 3 chance of invasive bacterial infection. Children with the mild pneumonia syndrome and a false positive malaria slide would have a 1 in 10 chance. The unreliability of malaria microscopy in practice further considerably strengthens the case for following syndromic indications for antibiotic treatment, irrespective of the malaria slide result

Among those with an axillary temperature $\geq 39^{\circ} \mathrm{C}$ but without a defined syndromic indication for antibiotics, an accurate malaria slide may be helpful in deciding on antibiotic treatment: 1 in 10 of those with a negative malaria slide had an "occult" invasive bacterial infection, whereas invasive bacterial infection was rare in children with positive slides and the outcome significantly better, although we did not establish how many of these children actually received antibiotics.

\section{Does a syndrome indicating antibiotic treatment justify withholding antimalarials?}

A third of children with a syndrome requiring antibiotics had a $P$ falciparum parasitaemia, and $24 \%$ of the deaths in this group were due to malaria in the absence of invasive bacterial infection. Thus, among children admitted to hospital, suspected or microscopically confirmed malaria should be treated with antimalarials regardless of any antibiotic treatment. Where the results of a malaria slide are unreliable, children with features of severe malaria (impaired consciousness, deep breathing, or both) should receive both parenteral antimalarials and antibiotics. Oral antimalarials are likely to be adequate for those not classified as severe.

\section{Meningitis: problems with clinical diagnosis and antimicrobial resistance}

One in four cases of meningitis presented without a clinical syndrome indicating parenteral antibiotic treatment. Results were similar when more detailed clinical indicators of meningitis were studied in this hospital. ${ }^{24}$ Meningitis was identified because our lumbar puncture protocol was broader than the syndrome definition, including suspicion of meningitis arising after admission. The pivotal role of lumbar puncture in rationalising treatment underlines the need to improve the use of this investigation ${ }^{17}$ : $88 \%$ of children with the syndrome did not have meningitis. Lumbar puncture therefore permits considerable cost savings, especially where there is significant resistance to inexpensive antibiotics. ${ }^{25}$ The high sensitivity to amoxicillin-gentamicin associated with this syndrome reflects the proportion of children with bacteraemia but not meningitis. Interestingly, $H$ influenzae type $\mathrm{b}$ immunisation may reduce the need for more expensive antibiotics such as third generation cephalosporins.

\section{Conclusions}

We have shown that simple rules based on a hierarchical classification of WHO integrated management of childhood illness clinical syndromes can target admissions with invasive bacterial infections and those at risk of death. Our findings in this study, and previous studies, ${ }^{215}$ indicate that the antibiotic management of children admitted to hospital in settings with no or few diagnostic resources should reflect a comprehensive assessment of the sick child and not focus on single diseases. A checklist illustrating such an approach is shown in the box. Our data are limited by being from one district hospital and using in vitro susceptibility testing (E-test). Similar studies are needed from other ecological zones in sub-Saharan Africa, especially areas with different prevalences of malaria and HIV. The potential impact on the aetiology of invasive bacterial infections of improved preventive strategies such as immunisation and changing patterns of resistance underscore the need for sustained surveillance in countries such as Kenya.

We thank the medical officer of health, hospital superintendent, and the clinicians, clinical assistants, and nursing staff of Kilifi District Hospital. We thank the director of the Centre for Geographic Medicine Research (coast), Norbert Peshu, for his support and guidance. We thank Tony Hart for his advice and support. This paper is published with the permission of the Director of the Kenya Medical Research Institute.

Contributors: JAB and ME designed the study, participated in patient care, interpreted the findings, and wrote the report. JAB also collected and analysed the data. KMaitland, IM, JAGS, KMarsh, and CRJCN participated in and supervised patient care and data collection and contributed to the interpretation of findings and writing of the report. BSL was responsible for all in house laboratory procedures and data collection and participated in interpretation of the data and the final report. SM and CN did the bacteriological analyses, including E-tests, and participated in the interpretation of these data and in writing the report. JAB is the guarantor.

Funding: The study was supported by the Kenya Medical Research Institute and the Wellcome Trust. The funding sources had no role in study design; in the collection, analysis, and interpretation of data; in the writing of the report; or in the decision to submit the paper for publication.

Checklist for a syndromic, non-single disease approach to the management of children admitted to hospital

All of these questions should be answered for all children ill enough to warrant admission to hospital

- Does this child need immediate cardiopulmonary resuscitation (airway, breathing, circulation), including oxygen, fluid resuscitation, urgent blood transfusion*, glucose, or anticonvulsants? ${ }^{26-28}$

- Does this child meet criteria for a clinical syndrome(s) requiring antibiotic treatment? The types of antibiotic and route of administration will depend on the clinical syndrome- treat the most severe classification

- Does this child have a clinical syndrome indicating antimalarial treatment? The need for antimalarials will depend on a history of fever (presumptive treatment) or having reliable microscopy. The type of drug and route of administration will depend on whether or not signs of severe malaria (impaired consciousness, deep "acidotic" breathing, or both) are present ${ }^{29}$

- Is this child severely malnourished? WHO recommends that protocols for drugs, fluids, and nutritional support should be followed for children with severe malnutrition, even if treatments for malaria or bacterial syndromes are being given

- Does this child have another obvious diagnosis?

- Does this child need a lumbar puncture to diagnose or exclude meningitis?24

- What maintenance oxygen, fluids, glucose, anticonvulsants, haematinics, or other drugs are needed?

- What level of observation or monitoring does this child need?

- When should this child be reviewed?

*Fluid resuscitation and blood transfusion protocols vary with the presence or absence of severe malnutrition 


\section{What is already known on this topic}

Local data on bacterial aetiology and antimicrobial susceptibilities of childhood diseases are sparse in sub-Saharan Africa

Treatment guidelines for children in this setting tend to focus on individual diseases, which may lead to uncertainty where several causes of illness are possible

The clinical manifestations of severe malaria overlap with those of invasive bacterial infection, and malaria microscopy may be unreliable, causing further uncertainty

\section{What this study adds}

A simple hierarchical classification of clinical syndromes seems to effectively target admissions with invasive bacterial infection and those at risk of death

A positive malaria slide does not seem to justify withholding parenteral antibiotic treatment where it is indicated by a syndrome requiring antibiotics

A practical approach is to make separate decisions regarding antibiotic, antimalarial, and other treatments on the basis of the presence of defined clinical syndromes and the results of any reliable laboratory investigations

Competing interests: None declared.

Ethical approval: The Kenya Medical Research Institute national ethical and scientific review committees approved the study.

1 World Health Organization. Management of the child with a serious infection or severe mal nutrition: guidelines at the first referral level in developing countries. Geneva: WHO, 2000.

2 English M, Berkley J, Mwangi I, Mohammed S, Ahmed M, Osier F, et al. Hypothetical performance of syndrome-based management of acute paediatric admissions of children aged more than 60 days in a Kenyan district hospital. Bull WHO 2003;81:16673.

3 Molyneux ME, Taylor TE, Wirima JJ, Borgstein A. Clinical features and prognostic indicators in paediatric cerebral malaria: a study of 131 comatose Malawian children. QJ Med 1989;71:441-59.

4 Marsh K, Forster D, Waruiru C, Mwangi I, Winstanley M, Marsh V, et al. Indicators of life-threatening malaria in African children. N Engl J Med 1995;332:1399-404.

5 O'Dempsey TJ, McArdle TF, Laurence BE, Lamont AC, Todd JE, Greenwood BM Overlap in the clinical features of pneumonia and malaria in African children. Trans $R$ Soc Trop Med Hyg 1993;87:662-5.

6 English M, Punt J, Mwangi I, McHugh K, Marsh K. Clinical overlap between malaria and severe pneumonia in Africa children in hospital. Trans $R$ Soc Trop Med Hyg 1996;90:658-62.

7 Perkins BA, Zucker JR, Otieno J, Jafari HS, Paxton L, Redd SC, et al Evaluation of an algorithm for integrated management of childhood illness in an area of Kenva with high malaria transmission. Bull World Health Organ 1997:75(suppl 1):33-42.

8 Kallander K, Nsungwa-Sabiiti J, Peterson S. Symptom overlap for malaria and pneumonia-policy implications for home management strategies. Acta Trop 2004;90:211-4.
9 Berkley J, Mwarumba S, Bramham K, Lowe B, Marsh K. Bacteraemia complicating severe malaria in children. Trans R Soc Trop Med Hyg 1999;93:283-6.

10 Evans JA, Adusei A, Timmann C, May J, Mack D, Agbenyega T, et al. High mortality of infant bacteraemia clinically indistinguishable from severe malaria. $Q J \mathrm{Med}$ 2004;97:591-7.

11 Berkley JA, Mwangi I, Mellington F, Mwarumba S, Marsh K. Cerebral malaria versus bacterial meningitis in children with impaired consciousness. QJ Med 1999;92:151-7.

12 Prada J, Alabi SA, Bienzle U. Bacterial strains isolated from blood cultures of Nigerian children with cerebral malaria. Lancet 1993;342:1114.

13 Mbogo CM, Mwangangi JM, Nzovu J, Gu W, Yan G, Gunter JT, et al. Spatial and temporal heterogeneity of Anopheles mosquitoes and Plasmodium falciparum transmission ral heterogeneity of Anopheles mosquitoes and Plasmodiun
along the Kenyan coast. Am J Trop Med Hyg 2003;68:734-42.

14 Ministry of Health, Republic of Kenva. AIIDS in Kenya. 6th ed. Nairobi: Government of Kenya, 2001.

15 Berkley JA, Ross A, Mwangi I, Osier F, Ahmed M, Shebbe M, et al. Prognostic indicators of early and late death in children admitted to a Kenyan district hospital. BMJ 2003;326:361-7

16 Berkley JA, Lowe BS, Mwangi I, Williams T, Bauni E, Mwarumba S, et al. Bacteremia among children admitted to a rural hospital in Kenya. N Engl J Med 2005;352:39-47.

17 Berkley JA, Mwangi I, Mwarumba S, Lowe B, Marsh K, Newton CRJC. Diagnosis of acute bacterial meningitis in children at a district hospital in sub-Saharan Africa. Lancet 2001;357:1753-7.

18 National Committee of Clinical and Laboratory Standards. M100-S7: performance standards for antimicrobial testing. Pennsylvania, USA: NCCLS, 1997.

19 Tulloch J. Integrated approach to child health in developing countries. Lancet 1999;354(suppl 2):16-20.

20 Falade AG, Mulholland EK, Adegbola RA, Greenwood BM. Bacterial isolates from blood and lung aspirate cultures in Gambian children with lobar pneumonia. Ann Trop Paediatr 1997;17:315-9.

21 Falade AG, Adegbola RA, Mulholland EK, Greenwood BM. Respiratory rate as a predictor of positive lung aspirates in young Gambian children with lobar pneumonia. Ann Trop Paediatr 2001;21:293-7.

22 Makani J, Matuja W, Liyombo E, Snow RW, Marsh K, Warrell DA. Admission diagnosis of cerebral malaria in adults in an endemic area of Tanzania: implications and clinical description. $O$ J Med 2003;96:355-62.

23 Reyburn H, Mbatia R, Drakeley C, Carneiro I, Mwakasungula E, Mwerinde O, et al. Overdiagnosis of malaria in patients with severe febrile illness in Tanzania: a prospective study. BMJ 2004;329:1212.

24 Berkley JA, Versteeg AC, Mwangi I, Lowe BS, Newton CR. Indicators of acute bacterial meningitis in children at a rural Kenyan district hospital. Pediatrics 2004;114:e713-9.

25 Duke T, Micheal A, Mokela D, Wal T, Reeder J. Chloramphenicol or ceftriaxone, or both, as treatment for meningitis in developing countries. Arch Dis Child 2003;88:536-9.

26 Advanced paediatric life support: the practical approach. 1st ed. London: BMJ Publishing Group, 1993.

27 Tamburlini G, Di Mario S, Maggi RS, Vilarim JN, Gove S. Evaluation of guidelines for emergency triage assessment and treatment in developing countries. Arch Dis Child 1999;81:478-82.

28 Robertson MA, Molyneux EM. Triage in the developing world-can it be done? Arch Dis Child 2001;85:218-3.

29 World Health Organization. Severe falciparum malaria. Trans Royal Soc Trop Med Hyg 2000;94(suppl 1).

(Accepted 22 February 2005)

doi $10.1136 /$ bmj.38408.471991.8F

Centre for Geographic Medicine Research (coast), PO Box 230, Kilifi, Kenya

James A Berkley clinical research fellow

Kathryn Maitland clinical research fellow

Isaiah Mwangi clinical researcher

Caroline Ngetsa laboratory technologist

Saleem Mwarumba laboratory technologist

Brett S Lowe laboratory manager

Charles RJC Newton senior clinical research fellow

Kevin Marsh professor

J Anthony G Scott clinical research fellow

Mike English clinical research fellow

Correspondence to:J A Berkley jberkley@kilifi.mimcom.net 